Check for updates

Cite this: React. Chem. Eng., 2017, 2, 295

Received 13th February 2017,

Accepted 6th March 2017

DOI: $10.1039 / \mathrm{c} 7 \mathrm{re00020k}$

rsc.li/reaction-engineering

\section{Flow synthesis of cyclobutanones via [2 + 2] cycloaddition of keteneiminium salts and ethylene gas $\uparrow$}

\author{
C. Battilocchio, ${ }^{a}$ G. Iannucci, ${ }^{a}$ S. Wang, ${ }^{a}$ E. Godineau, ${ }^{\text {b }}$ A. Kolleth, ${ }^{\text {b }}$ \\ A. De Mesmaeker ${ }^{b}$ and S. V. Ley ${ }^{\star a}$
}

A flow chemistry process for the synthesis of 2-substituted cyclobutanones, via [2 + 2] cycloaddition of keteneiminium salts and ethylene gas, is reported. Our approach uses rapid and mild reaction conditions to access a diverse array of products with good to excellent yield, alongside a good level of functional group compatibility.

In recent years, there has been a resurgence in the importance of small rings in chemistry programmes. ${ }^{1}$ In particular, from a pharmaceutical and agrochemical perspective there is interest in developing new methods to access these molecular entities, ${ }^{2}$ with a focus towards developing more sustainable processes. In addition, the general demand to generate flexible building blocks, susceptible to further molecular elaboration, is driving the science in this area. ${ }^{3}$ Cyclobutanones represent an interesting class of small rings ${ }^{4}$ as they are associated with a reactive versatility, ${ }^{5}$ mainly due to their ring strain $\left(c a .25 \mathrm{kcal} \mathrm{mol}^{-1}\right)^{4}$ (Fig. 1).

As part of an ongoing research programme, we became interested in the preparation of mono-substituted cyclobutanones as a generally underexplored class of small rings. We were interested in developing a reliable and robust procedure to the preparation of mono-substituted cyclobutanones, minimising risks and providing a potentially scalable process.

A classical approach to these systems involves cycloaddition reactions of ketene intermediates ${ }^{6}$ or, more effectively, keteneiminium salts species. ${ }^{7}$ In the latter case, Ghosez ${ }^{7 a-d}$ and co-workers have pioneered the use of keteneiminium salts and alkenes in $[2+2]$ cycloadditions for the generation

\footnotetext{
${ }^{a}$ Innovative Technology Centre, Department of Chemistry, University of Cambridge, Lensfield Road, CB2 1EW, UK. E-mail: svl1000@cam.ac.uk

${ }^{b}$ Syngenta Crop Protection AG, Crop Protection Research, Schaffhauserstrasse 101, CH-4332, Switzerland

$\uparrow$ Additional data is available from the University of Cambridge Data Repository website: https://doi.org/10.17863/CAM.7110. Electronic supplementary information (ESI) available: Reactions set up and compounds characterisation. See DOI: 10.1039/c7re00020k
}

of substituted cyclobutanones (Scheme 1). Although these protocols provide an insightful approach towards the making of this scaffold, there are clear issues related to the original batch methods. Whilst the use of triflic anhydride on a small batch scale is acceptable, dosing at large scales can be quite problematic. Also, as the preparation of mono-substituted cyclobutanones requires the use of ethylene gas, there are clear safety issues associated with the use of flammable gaseous reagents. ${ }^{7 b}$

On the other hand, the advent of new technologies and advanced synthesis equipment ${ }^{8,9}$ has opened improved safety windows.

Based on our expertise in the use of these enabling methods to solve chemical synthesis problems, ${ }^{8}$ we undertook a program to study the preparation of 2-monosubstituted cyclobutanones with the use of the tube-in-tube ${ }^{10}$ technology as an advantageous gas-feeding method for chemical reactions, which overcomes reactive gas handling issues. ${ }^{10 a}$ More precisely, the approach focused on the use of a standard flow system with in-line tube-in-tube reactor to control the introduction of ethylene gas (Scheme 2).

Previous investigations highlighted the importance of using bis-allyl amides, as precursors on these cycloaddition reactions, to afford a reasonably yielding process. ${ }^{7 h}$ For the

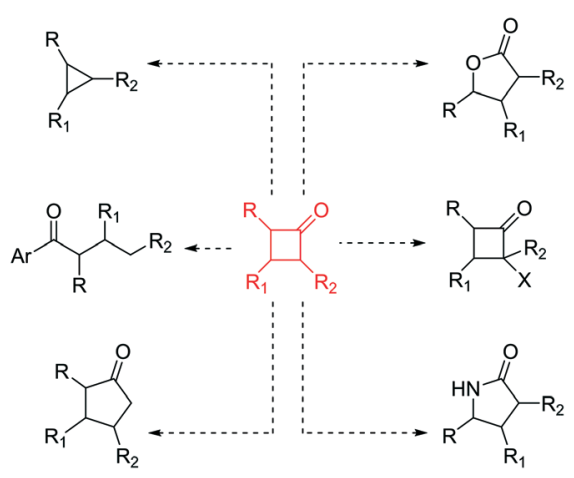

Fig. 1 Chemical versatility of cyclobutanones. ${ }^{4,5}$ 
a)

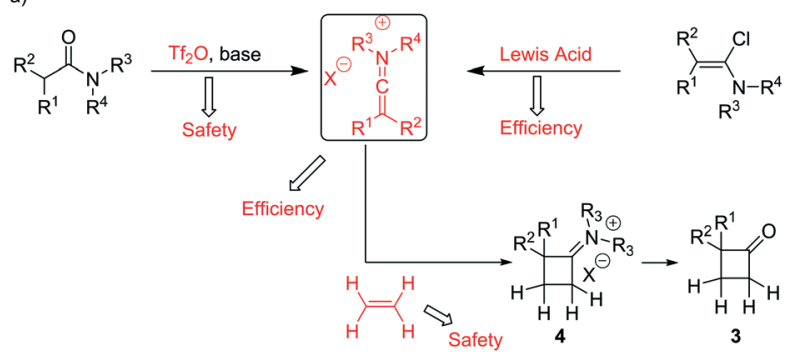

b)

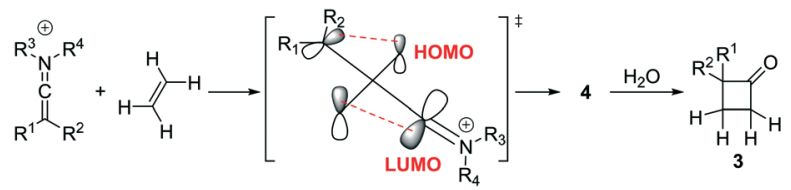

Scheme 1 a) Synthesis strategies for the preparation of monosubstituted cyclobutanones and b) mechanistic overview for the cycloaddition of keteniminium salts and ethylene.
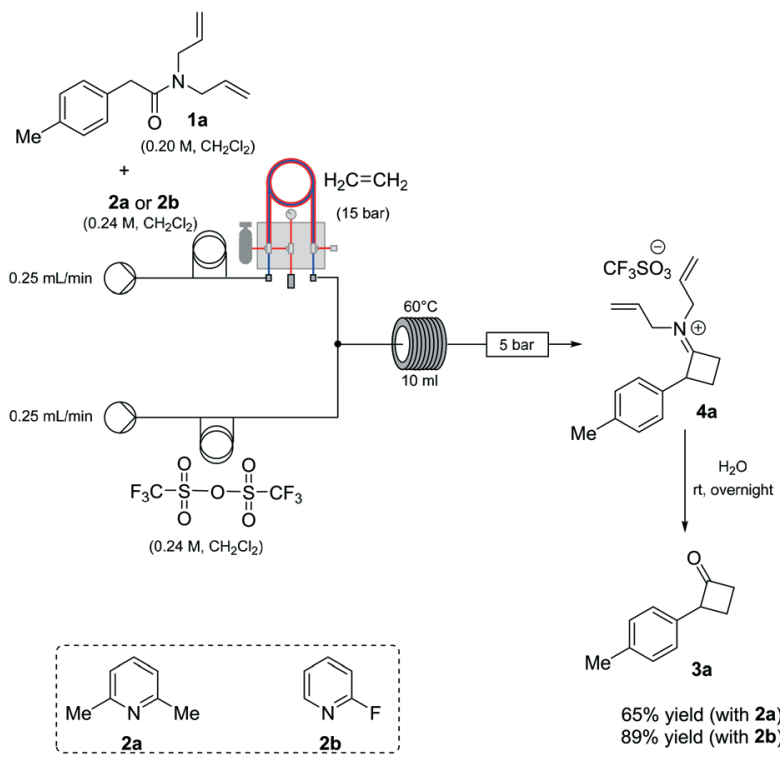

$65 \%$ yield (with 2 a)
$89 \%$ yield (with 2 b)

Scheme 2 Machine-assisted reaction set up for screening.

first set of experiments, we explored the use of 2,6-lutidine as an additive base, particularly owing to its low cost.

Whilst ethylene gas was dosed using the tube-in-tube reactor, triflic anhydride and the reagents were loaded via $10 \mathrm{~mL}$ reaction loops. A first screening of conditions highlighted that temperature, residence time and pressure were all crucial parameters. The best reaction profile was obtained at 60 ${ }^{\circ} \mathrm{C}$, whilst reducing or increasing the temperature gave no benefits to the overall reaction. We identified the optimum residence time to be $20 \mathrm{~min}$, with a pressure differential of 10 bar (see Table S1 in the ESI $\dagger$ ). However, as shown in Scheme 2, our attempts to optimise the reaction conditions beyond $65 \%$ for the preparation of $3 a$ were not successful nor with other amides could this be improved.
An analysis of the reaction mechanism suggested the basicity of the 2,6-lutidine may be an obstacle to the reaction outcome, as noted in previous works. ${ }^{7 d-h}$ Consequently, switching to 2-fluoropyridine ${ }^{11}$ afforded a process that could be applied to a wide range of substituted amides, mostly in high isolated yields (Fig. 2). We then extended our investigation to study the reaction scope with respect to the aromatic acetic precursors (Fig. 2). Under these new conditions, a $0.2 \mathrm{M}$ solution of amide $1 \mathrm{a}$ (containing 1.2 equiv. of 2-fluoropyridine) was pumped $(0.25 \mathrm{~mL} / \mathrm{min})$ through the tube-in-tube system where ethylene gas was fed at a pressure differential of 10 bar and the solution directed to a T-piece where it combined with a solution of triflic anhydride $(0.25$ $\mathrm{mL} / \mathrm{min}) ;$ the reaction stream was then reacted in a $10 \mathrm{~mL}$ coil reactor at $60{ }^{\circ} \mathrm{C}$ for $20 \mathrm{~min}$. The output of the reaction was directed to a quenching pot which contained distilled water. Under these conditions, compound 3a was obtained with an improved $89 \%$ yield.

The presence of both-electron-rich and electron-poor substituents was tolerated, giving acceptable yields in all cases. In general, the presence of electron-rich aromatic rings was associated with slightly better outcomes. The protocol tolerated hetero-aromatic rings ( $3 \mathrm{c}$ and $3 \mathrm{~h}, 92 \%$ and $65 \%$ yield respectively) and proved to be suitable for bis-derivatives (3g, $78 \%$ yield). The presence of ortho-substituents gave product $3 \mathbf{i}$ in slightly lower yield ( $51 \%$ isolated).

Next, we increased further the scope of the method using aliphatic derivatives (Fig. 3). Generally, these derivatives gave good yields with no major by-products being detected. The presence of ester and halogen groups was well tolerated, with compounds 31 and $3 \mathrm{~m}$ being obtained with good yields (52\% and $68 \%$, respectively). An interesting example containing a terminal alkyne moiety, readily afforded $3 p$ ( $47 \%$ yield).
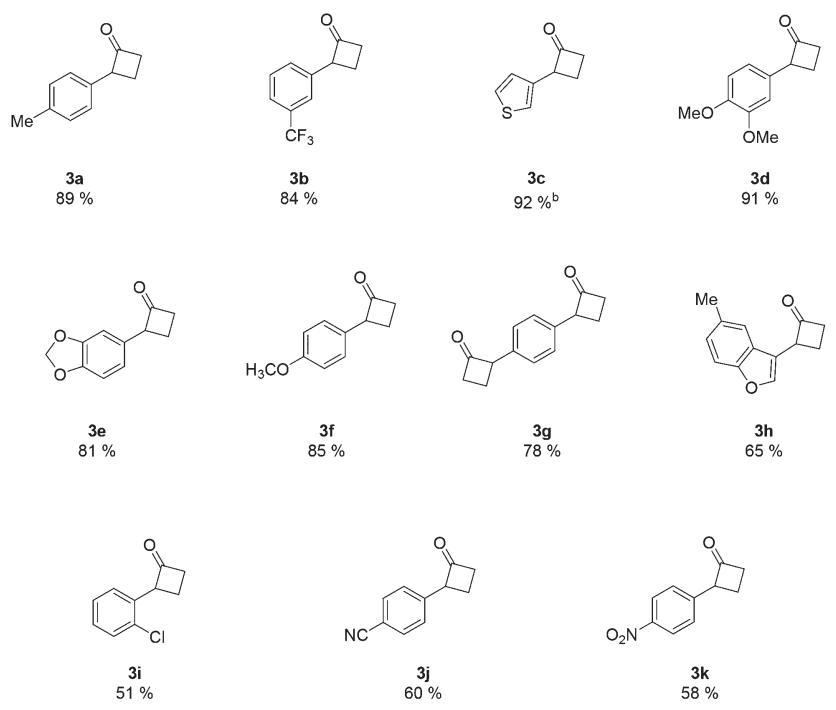

${ }^{a}$ Reaction was run on $2 \mathrm{mmol}$ scale; ${ }^{b}$ Reaction was run on $28 \mathrm{mmol}$ scale

Fig. 2 Scope of the reaction with respect to the use of aryl acetic amides $^{\mathrm{a}}$. 

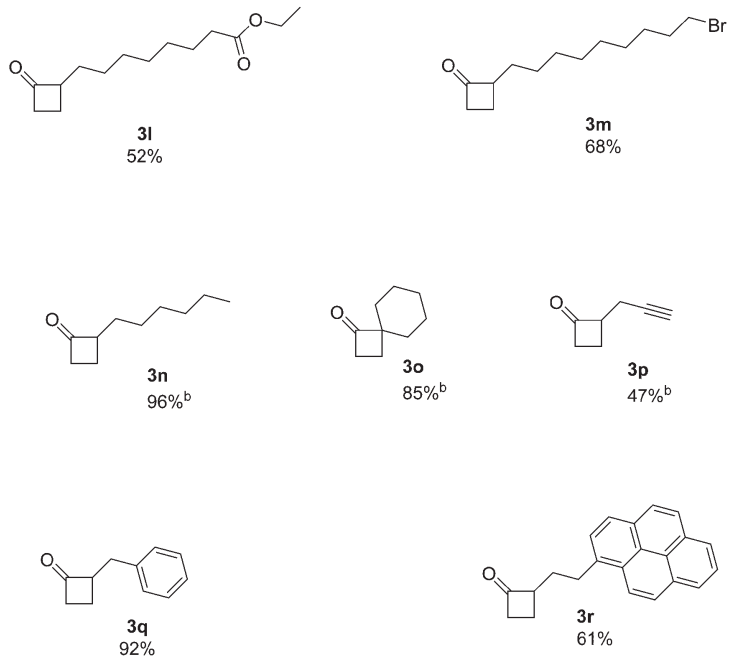

${ }^{a}$ Reaction were run on $2 \mathrm{mmol}$ scale; ${ }^{\mathrm{b}}{ }^{1} \mathrm{H}$-NMR yield (Internal standard $=1,3,5$ trimethoxybenzene)

Fig. 3 Expanding the scope of the reaction ${ }^{a}$.

Moreover, 2-alkylcyclobutanones (2-ACBs), such as 2-hexylcyclobutanone (3n, 96\% yield), represent important markers for the analysis of irradiated food; this protocol can easily apply to the synthesis of such compounds, where previous methods of synthesis failed to provide reasonable yields. $^{12}$

To prove the robustness of method, we examined the ability of the machine-assisted method to afford larger amounts of material, obtaining $3.92 \mathrm{~g}$ of $3 \mathrm{c}$ in a consistent $92 \%$ yield (Scheme 3). To make the system fully continuous, we collected the iminium intermediate $4 \mathrm{c}$ in a reservoir and then

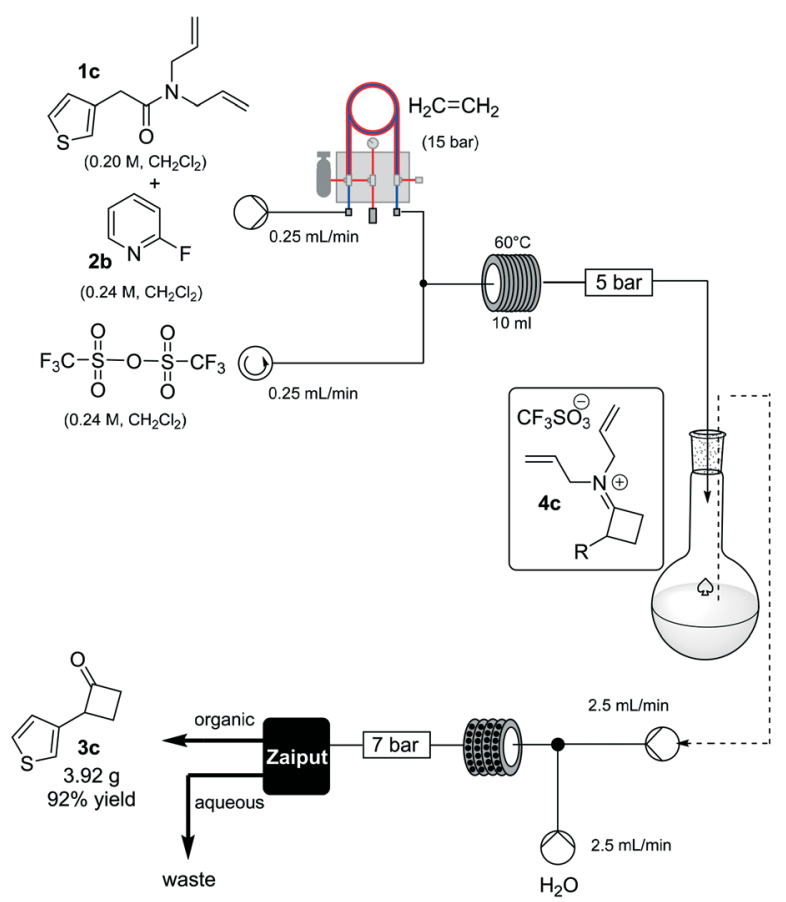

Scheme 3 Scale up to afford compound 3c. combined the organic solution with an aqueous stream (2.5 $\mathrm{mL} / \mathrm{min}$ flow rate for each channel), reacting the biphasic mixture at $80{ }^{\circ} \mathrm{C}$ in a static-mixer coil ${ }^{13}(35 \mathrm{~mL}, 7$ min residence time) (see ESI†े), and used a membrane-based liquidliquid separator to continuously collect the organic output. ${ }^{14}$

In conclusion, we have developed a safe and reliable route for the generation of mono-substituted cyclobutanones, using ethylene as gaseous coupling partner. The use of flow chemistry and the combination of the tube-in-tube technology clearly offers advantages of safety, reproducibility and potential scalability.

The authors would like to thank Syngenta Crop Protection (CB) and the EPSRC (SVL, grants EP/K009494/1, EP/M004120/ 1 and $\mathrm{EP} / \mathrm{K} 039520 / 1$ ) for financial support.

\section{Notes and references}

$\ddagger$ The solution containing triflic anhydride was pumped with a peristaltic pump; the polymer tubing must tolerate this reagent. In our case, we used a SF-10 pump from Vapourtec (https://www.vapourtec.com/), with the red tubing.

1 (a) T. Rodrigues, D. Reker, P. Schneider and G. Schneider, Nat. Chem., 2016, 8, 531-541; (b) A. Figueras, R. MirallesLlumà, R. Flores, A. Rustullet, F. Busqué, M. Figueredo, J. Font, R. Alibés and J.-D. Maréchal, ChemMedChem, 2012, 7, 1044-1056.

2 (a) L. Malet-Sanz and F. Susanne, J. Med. Chem., 2012, 55, 4062-4098; (b) D. E. Fitzpatrick, C. Battilocchio and S. V. Ley, ACS Cent. Sci., 2016, 2, 131-138.

3 (a) A. Guan, C. Liu, X. Yang and M. Dekeyser, Chem. Rev., 2014, 114, 7079; (b) C. Lamberth, S. Jeanmart, T. Luksch and A. Plant, Science, 2013, 341, 742.

4 (a) D. Bellus and B. Ernst, Angew. Chem., Int. Ed. Engl, 1988, 27, 797-827; (b) F. Secci, A. Frongia and P. P. Piras, Molecules, 2013, 18, 15541-15572.

5 (a) M. H. Shaw and J. F. Bower, Chem. Commun., 2016, 52, 10817-10829; (b) H. M. Ko and G. Dong, Nat. Chem., 2014, 6, 739-744; (c) M. Murakami, T. Itahashi and Y. Ito, J. Am. Chem. Soc., 2002, 124, 13976-13977; (d) R. C. D. Brown, C. J. R. Bataille and J. D. Hinks, Tetrahedron Lett., 2001, 42, 473-475; (e) B. Brown and L. S. Hegedus, J. Org. Chem., 2000, 65, 1865-1872.

6 M. D. Lawlor, T. W. Lee and R. L. Danheiser, J. Org. Chem., 2000, 65, 4375-4384.

7 (a) J. Marchand-Brynaert and L. Ghosez, J. Am. Chem. Soc., 1972, 94, 2870-2872; (b) J.-B. Falmagne, J. Escudero, S. Taleb-Sahraoui and L. Ghosez, Angew. Chem., Int. Ed. Engl., 1981, 20, 879-880; (c) A. Sidani, J. Marchand-Brynaert and L. Ghosez, Angew. Chem., Int. Ed. Engl., 1974, 13, 267; (d) C. Genicot and L. Ghosez, Tetrahedron Lett., 1992, 33, 7357-7360; (e) A. Lumbroso, S. Catak, S. Sulzer-Mossé and A. De Mesmaeker, Tetrahedron Lett., 2014, 55, 5147-5150; $(f)$ A. Lumbroso, S. Catak, S. Sulzer-Mossé and A. De Mesmaeker, Tetrahedron Lett., 2014, 55, 6721-6725; (g) A. Lumbroso, S. Catak, S. Sulzer-Mossé and A. De Mesmaeker, Tetrahedron Lett., 2015, 56, 2397-2401; (h) A. Kolleth, A. 
Lumbroso, G. Tanriver, S. Catak, S. Sulzer-Mossé and A. De Mesmaeker, Tetrahedron Lett., 2016, 57, 3510-3514.

8 For selected reviews regarding enabling synthesis technologies, see: (a) M. Movsisyan, E. I. P. Delbeke, J. K. E. T. Berton, C. Battilocchio, S. V. Ley and C. V. Stevens, Chem. Soc. Rev., 2016, 45, 4892-4928; (b) M. Baumann and I. R. Baxendale, Beilstein J. Org. Chem., 2015, 11, 1194-1219; (c) S. V. Ley, D. E. Fitzpatrick, R. M. Myers, C. Battilocchio and R. J. Ingham, Angew. Chem., Int. Ed., 2015, 54, 10122-10136; (d) V. Hessel, D. Kralisch, N. Kockmann, T. Noël and Q. Wang, ChemSusChem, 2013, 6, 746-789; (e) J. C. Pastre, D. L. Browne and S. V. Ley, Chem. Soc. Rev., 2013, 42, 8801-8869; $(f)$ D. Webb and T. F. Jamison, Chem. Sci., 2010, 1, 675-680; $(g)$ R. L. Hartman, J. P. McMullen and K. F. Jensen, Angew. Chem., Int. Ed., 2011, 50, 7502-7519.

9 For selected recent examples from our group, see: (a) C. Battilocchio, S.-H. Lau, J. M. Hawkins and S. V. Ley, Org. Synth., 2017, 94, 34-45; (b) C. Battilocchio, F. Feist, A. Hafner, M. Simon, D. N. Tran, D. M. Allwood, D. C. Blakemore and S. V. Ley, Nat. Chem., 2016, 8, 360-367; (c) T. Ouchi, R. J. Mutton, V. Rojas, D. E. Fitzpatrick, D. G. Cork, C. Battilocchio and S. V. Ley, ACS Sustainable Chem. Eng., 2016, 4, 1912-1916; (d) S.-H. Lau, A. Galván, R. R. Merchant, C. Battilocchio, J. A. Souto, M. B. Berry and S. V. Ley, Org. Lett., 2015, 17, 3218-3221; (e) T. Ouchi, C. Battilocchio, J. M. Hawkins and S. V. Ley, Org. Process Res. Dev., 2014, 18, 1560-1566; $(f)$ R. Chorgade, C. Battilocchio, J. M. Hawkins and S. V. Ley, Org. Lett., 2013, 15,
5698-5701; (g) C. Battilocchio, I. R. Baxendale, M. Biava, M. O. Kitching and S. V. Ley, Org. Process Res. Dev., 2012, 16, 798-810.

10 (a) M. Brzozowski, M. O'Brien, S. V. Ley and A. Polyzos, Acc. Chem. Res., 2015, 48, 349-362; (b) C. Schotten, D. Plaza, S. Manzini, S. P. Nolan, S. V. Ley, D. L. Browne and A. Lapkin, ACS Sustainable Chem. Eng., 2015, 3, 1453-1459; (c) J. C. Pastre, D. L. Browne, M. O'Brien and S. V. Ley, Org. Process Res. Dev., 2013, 17, 1183-1191; (d) S. L. Bourne, M. O'Brien, S. Kasinathan, P. Koos, P. Tolstoy, D. X. Hu, R. W. Bates, B. Martin, B. Schenkel and S. V. Ley, ChemCatChem, 2013, 5, 159-172.

11 (a) B. Peng, D. Geerdink and N. Maulide, J. Am. Chem. Soc., 2013, 135, 14968-14971; (b) B. Peng, D. Geerdink, C. Farès and N. Maulide, Angew. Chem., Int. Ed., 2014, 21, 5462-5466.

12 (a) M. Miesch, B. Ndiaye, C. Hasselmann and E. Marchioni, Radiat. Phys. Chem., 1999, 55, 337-344; (b) A. Hartwig, A. Pelzer, D. Burnouf, H. Titeeca, H. Delincee, K. Briviba, C. Soika, C. Hodapp, F. Raul, M. Miesch, D. Werner, P. Horvatovich and E. Marchioni, Food Chem. Toxicol, 2007, 45, 2581-2591; (c) E. M. K. Leung, P. N. Y. Tang, Y. Ye and W. Chan, J. Agric. Food Chem., 2013, 61, 9950-9954; (d) A. Breidbach and F. Ulberth, Food Chem., 2016, 201, 52-58;

(e) X. Meng and W. Chan, Food Chem., 2017, 217, 352-359.

13 The static mixer reactors are available from Vapourtec Ltd (https://www.vapourtec.com/).

14 The membrane-based liquid-liquid separator was supplied by Zaiput Flow Technologies (http://www.zaiput.com/). 